\title{
Analytical Study on Improving Expertise of University Students through Innovative Training Project -Centered on Game Design
}

\author{
YANG Yuan \\ Sino-Korean School of Multimedia Design \\ Shanghai University of Engineering Science, \\ Shanghai, China \\ yoyo810608@163.com
}

\begin{abstract}
In this paper, the detailed process of college students' innovative training programs is introduced, including the application, initiation and completion. Game design and production is a long, complicated and hard process after which users are brought into a brand new electronic entertainment world by innovative elements. Innovative programs for game design majors are mainly analyzed. Three program cases are specially introduced and explained. The approaches and procedures of designing innovative programs for game design majors are summarized to expound and prove the importance of innovative programs in improving college students' professional and practical abilities. Based on the teaching features of the game design major as well as the concrete process and implementation requirements of innovative training project themed with game design, in combination with the generalization and summarization of actual innovative training project cases of several groups of university students, the significant role of innovative training project themed with game design in the practicable ability of university students is demonstrated.
\end{abstract}

Keywords - innovative training program; game design; game character design; game scene design; practical ability; design style

\section{INTRODUCTION}

The innovative training project for university students refers to the independent completion of the innovative research project design, preparation for the research, project implementation, research report writing, result (academic) communication, and other relevant work fulfilled by university students in the form of individual or team, under the guidance of faculty advisors. The innovative training project is designated to cultivate and strengthen the independent innovation

Cultivate consciousness, innovation spirit, practical ability, team cooperation ability and communication ability of university students. Currently, the innovative training project for university students mainly consists of three categories, municipal innovative training project, key scientific research platform-based innovative training project for university students, and campus-level innovative training project. Universities and colleges require the selected topic in the application form of innovative training project for university students to be creative, independent and exploratory, with novel ideas and clear goals. University students are encouraged to discover problems in life, present topics, and make inventions, innovations, research and development of practical application value. The project research scheme shall be advanced, reasonable, and feasible, with verifiable expected results.

The game design is an important approach for human being to popularize, understand, and even further the future culture. To cultivate the expertise of game designer, the relevant theory and practice of literature, art, design, and other subjects shall be reasonably complemented, so as to lay a solid foundation for the personal career development of students in the future. These innovative training projects strongly support for the theoretical foundation and practical ability of the students of colleges and universities. Since the topic selection, students give play to different cognitions and design thinking to the fullest possible extent under the guidance of teachers, and embody different imaginations and creativities, regardless of collaboration between team members or the design style and presentation of the projects.

\section{CONCRETE PROCESS AND IMPLEMENTATION REQUIREMENTS of GAME DESIGN PROJECTS}

The innovative training practice project for university students themed with game design aims to build up the independent artistic thinking, fully creative artistic expression and solid artistic practice of students in line with the principle of being dominated by the professional learning interest and enthusiasm of students and supplemented with the guidance of specialized teachers. From the very beginning of the innovative training project, namely, the project initiation, students independently determine the project topics, project approval basis, implementation scheme and the project innovation, and formulate the detailed experimental scheme and implementation plan. Students can gain deep insight into the complete process of projects through a series of professional practical training from project topic selection, project application to project production. Prior to the submission of formal application, faculty advisers shall repeatedly organize the applicant students to receive the guidance on the topic 
selection, distribute the application template to students as required, and guide their standardized completion of the application form. The applied topics of innovative training projects present a diversified trend, which applies the creative elements to all aspects of game design. The project involves the game design, game character design, 3D game scene design, Flash mini-game production, game programming and many other aspects. The concluding results of innovative training project are usually dominated by the game design paper, game image design works, game source file, and project research report published by students. Moreover, some characters and scene design works completed in certain projects also declare the design patent.

In the process of implementation of innovative training project, the role of faculty adviser mainly embodies in the supervision and guidance of innovative project, while the concrete implementation process is still oriented in students and dominated by the self-supervision between project team members, for the purpose of developing the self-learning and control ability of students over the game design. The effective guidance of academic advisers throughout the project implementation allows students of each team to clearly understand and know the contents and targets of their respective projects. All of team members can smoothly complete the project schedule by carefully listening to the organization and arrangement of the project leader. The implementation of innovative training project requires a great deal of patience and perseverance. At the preliminary stage of the project, for instance, the collection and collation of relevant data, consultancy with design literature, as well as calculation and analysis of data in the game planning are required. In addition to the division of labor and project arrangement, it is required to constantly enhance the self-learning, deliberation on the cultural content and true translation of design originality into game design work in the process of project.

\section{DESIGN AND ANALYSIS OF PROJECT}

The innovative training project themed with game design for university students shall adopt the heuristic method of teaching. The faculty adviser shall guide students to establish the implementation method of project under the premise of reasonable and effective thinking. The application and concrete production of project shall also proceed in combination with the prevailing advanced digital game production technology, popular film, television and animation works, and literary works to reflect the humanity and cultural lives of different ethnic groups and folk customs. The game design-oriented innovative training project seeks to cultivate the habit of students to carefully experience and observe lives, broaden students' thinking, and develop students' ability of thinking. The professional practice ability of students is enhanced by simulating the industry project.

\section{A. Game design project with an oriental ink style}

The design of Amaterasu is characterized by ink style with rich oriental implication, which is designed and produced around the game characters and game scenes. The project team consists of five members, who have a clear division of labor. In terms of design, the project team takes the supernatural or uncanny collected works and novels peculiar to China as a reference, such as The Classic of Mountains and Rivers, Journey to the West, Anecdotes about Spirits and Immortals and The Legend and the Hero. The scene and character modeling and coloring use the elements of ink and color painting for reference, with stiff and flexible lines, as shown in Fig. 1.[1] In the process of design, the team members, taking into account the aesthetic demand of players, manifest the design by both the ink style and proper addition of cartoon elements. For the prop design of characters, the imaginary space is expanded, which is not limited to the presentation of weapons, but also increases the interesting cartoon prop elements, such as fruits and animal models. For the design of game scene, a lot of different cultural and geographical backgrounds and environments are added, such as underwater mermaid palace, panda bamboo and ancient tomb. The way to play game also applies bold ideas and changes, and integrates the mechanical science design, thus allowing players to immerse into the natural and smooth dynamic and aesthetic perception from ink style and also experience the unity of lovely, pure, fresh, nostalgic and other various artistic techniques.
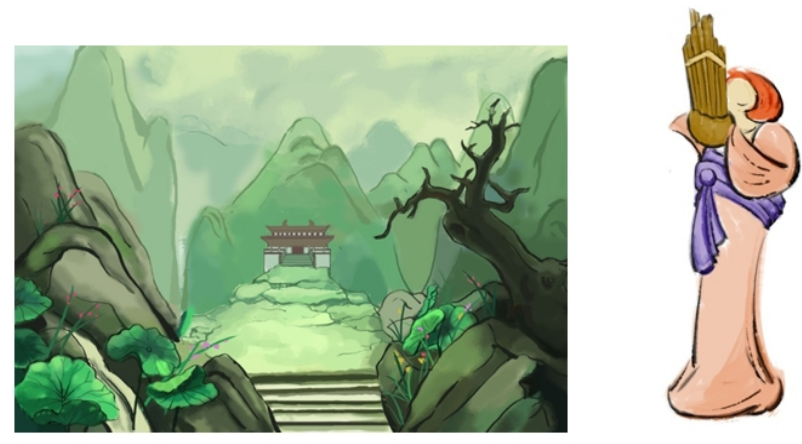

Fig. 1. Scene and Character Design of Amaterasu

\section{B. Game design project with a western steampunk style}

Day One is an innovative game reflecting the western steampunk. In the process of creation, the team members constantly accumulate and summarize the experience of design and production, and embody their wonderful thinking in the image of characters as well as the layout and coloring of scene in the form of paintbrush. At the early planning stage of the Day One, the team members list the required design elements. With more design elements and information to be considered, only a close teamwork can produce highly efficient and high-quality works. To this end, each team member has a clear division of labor, and everyone unfold their best parts. Through data access, collation and induction, the project team focuses on the presentation of two aspects: innovation consciousness and nostalgia. In terms of the mastery of steampunk nostalgic feeling, the team members equip each character with retro outfits, accessories, weapons and props. Each race has its own featured element peculiar to its style. Both the innovation consciousness and nostalgia are highlighted in the design, as shown in Fig. 2.[2] The project team combines the steampunk elements with the traditional and future elements, thus exhibiting the retro elements everywhere in the future world created. 

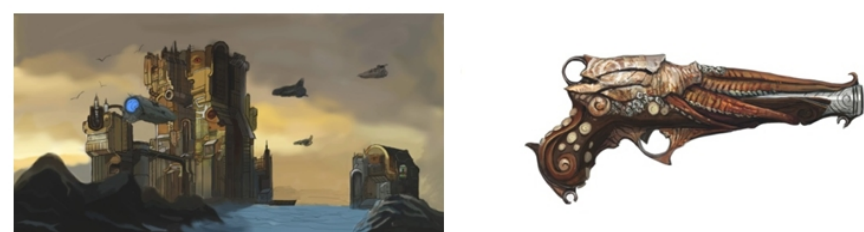

Fig. 2. Scene and Prop Design of Day One

\section{Game design project with Sino-western magic style}

The game Demon Hall is a project case of students, in which, Chinese and western magic style is attempted to be fused. The team members firstly resolve the problems encountered in the process of design through actual experience process, analyze the in-depth application of design methods by grouping experiment of different design methods of the same object, comparing results and reversing the design process, and in such a way, complete the concept art design of the series of games. For the design, Damon Hall attempts to organically bond the Chinese and western traditional and modern architecture, costumes, character modeling prototype, which embody the special cultural and artistic elements of China and western countries. [3] The project involves two teams, which support each other in the process of collaboration. The teams have clear division of labor and also coordinate with each other to facilitate the development of the project schedule. Fig 3 shows the design of game character in the project.

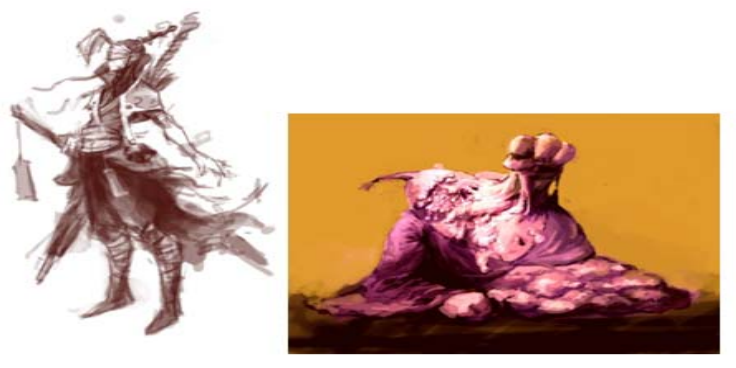

Fig. 3. Scene and Prop Design of Demon Hall

\section{Analysis on the Cultivation of Students' Ability}

The game design is eventually the perfect combination of art and technology. Both the design ideas and technique of expression are important to game designers. The game design is mainly centered on the learning of game art production, especially the concept art design, game character design, game scene design, 3D game production, special game effects rendering and other knowledge. The teaching shall focus on the cultivation of students' practical ability. In spite of the practical teaching, the skill of student to grasp and use the software of game image production often need to build on the good cognition and understanding of art, design theory, and design methods. If students blindly pursue for the operation of game software but ignore the learning of art and design theory, training of basic art skills, or the accumulation of literature, history and life common sense, such blind pursuit is bound to produce the illogical or unreasonable results notwithstanding many unrestrained ideas come up in the process of creation.

The innovative training project for university students motivate the passion of students to quickly engage in the specific production, and also impose the theoretical thinking requirements on students regarding the project production background, production process, production rationality, and the market research of design. Students gradually accumulate the cultural and artistic knowledge, train the logical thinking, and improve the comprehensive expertise through the deepening investigation of project contents and topics. The constant production and perfection of projects help students to develop a good professional self-study habit to the benefit of expanding personal professional learning space.

The innovative training project for university students is not only to create new things, but also to ponder over problems from a new perspective, and discover the root behind the appearance of each thing. Innovative thinking can broaden the horizon of students, and also bring with unceasing surprises to the work and study of students. The project is common to team members. Everyone has the same goal. In the cooperation, collision is inevitably because of the different views. In such a case, students shall attach most importance to the team and give priority to the project to fully dedicate to the project and sufficiently respect for every team member. Although many students are unfamiliar with each other at the beginning of the project establishment, they develop into good teammates or friends due to the participation in the innovative project for university students, which also witnesses the purpose of innovative project for university students - teamwork. The strength of every person is limited, but the team can gather up and maximize the energy of everyone.

\section{CONCLUSION}

The creativity of game design comes from life. University students are good at capturing the emerging things and giving play to creativity and imagination. They can gain various benefits from the practice of innovative activities, such as promoting the organization ability, improving the innovative thinking ability, establishing friendship through exchanges and communications, enriching themselves in the process of busy study and obtaining a lot of theoretical and practical knowledge outside of the classroom teaching. The production of innovative project allows students to learn about the basic project production process, master the preparation of project contract and project cost accounting, experience each link of project production and harvest fruitful project results. The innovative training project for university students enables students to foster the ability not only to acquire a large number of information resources, but also to reasonably and effectively integrate such information resources. They know how to present the creativity by use of technology and establish the ideal of becoming game artistic designers.

\section{REFERENCES}

[1] LIU De-chuan, YANG Yuan, Ink Style Manifestation in the Character Design of Original Game Amaterasu, Peony, 2016-3 issue, PP63-64

[2] XU Chen, YANG Yuan, Studies on the Design of Steampunk Style Character in the Original Game Day One, MING, 2016-3 issue (2), PP02

[3] FANG Yi-chen, YANG Yuan, Studies on Concept Art Design of Game Character - Taking the Original Game Demon Hall as an Example, Peony, 2015-12 issue, PP 89-90 